\title{
Response of water budget to recent climatic changes in the source region of the Yellow River
}

\author{
ZHOU DeGang* \& HUANG RongHui \\ Center for Monsoon System Research, Institute of Atmospheric Physics, Chinese Academy of Sciences, Beijing 100190, China
}

Received November 22, 2011; accepted February 2, 2012; published online March 31, 2012

\begin{abstract}
Discharge in the source region of the Yellow River significantly declined after 1990. China Meteorological Administration (CMA) data show that precipitation in this region was low in the 1990s but returned to above normal after 2002; in recent decades there has been rapid warming of surface air, moistening and wind speed decrease. To investigate the influences of recent climatic changes on the water budget, this study simulates the surface water budget at CMA stations within and surrounding the source region during 1960-2006, using an improved land surface model. Results indicate that the spatial pattern of precipitation change is an important factor (except for precipitation amount and intensity) in determining the response of runoff to precipitation changes. Low runoff in the 1990s was consistent with precipitation amount and intensity. The recovery of precipitation after 2002 is mainly from increased precipitation in the dry area of the source region. Evaporation was mainly limited by water availability in this dry area, and thus most of the precipitation increase was evaporated. By contrast, energy availability was a more important influence on evaporation in the wet area. There was more evaporation in the wet area because of rapid warming, although precipitation amount partly decreased and partly increased, contributing to the reduction of runoff after 2002. This control on evaporation and its response, together with the modified spatial pattern of precipitation, produced a water budget unfavorable for runoff generation in the source region during recent years.
\end{abstract}

water budget, spatial pattern of precipitation, Yellow River source region, climatic changes, runoff, evaporation

Citation: Zhou D G, Huang R H. Response of water budget to recent climatic changes in the source region of the Yellow River. Chin Sci Bull, 2012, 57: 21552162, doi: $10.1007 / \mathrm{s} 11434-012-5041-2$

The Yellow River is the second largest in China, and it is the vital water source for Northwest and North China. The source region of this river, a basin above Tangnag hydrologic station, comprises $16.2 \%$ of the total area and contributes more than $35 \%$ of total runoff [1]. It is widely regarded as the "water tower" of the Yellow River. Discharge in this source region declined significantly in the 1990s [2]. Therefore, determining the water budget response in this region to climatic change is essential to assessment of possibly significant economic and social impacts in North China.

The source region of the Yellow River is on the northeastern Tibetan Plateau (TP). Warming over the TP is generally more rapid than that of surrounding areas [3], which

\footnotetext{
*Corresponding author (email: degangzhou @163.com)
}

can cause an acceleration of the water cycle and redistribution of water resources [4]. Population density in the source region is sparse and the influence of human activities on the water budget is therefore negligible. The regional discharge reduction therefore reflects the influence of natural changes. Similar low runoff epochs have been identified in reconstructed streamflow over the last thousand years [5]. Numerous studies have addressed causes for the 1990s discharge decline. Most focused on climatic changes, especially variations of precipitation and surface air temperature [6-14]. It is well established that rainfall amount and intensity directly affect runoff $[7,13,14]$. However, there is disagreement among researchers as to the effect of warming on runoff $[7,8,10,12,14]$. Evaporation is key to this issue, but there is a lack in observation of actual evaporation. Furthermore, there is a paradox between the variation of meas- 
ured $20 \mathrm{~cm}$ pan evaporation [15] and actual evaporation [8, $16,17]$. Although there have been a few hydrologic simulations including the evaporation process for the region $[6,9,11]$, links between meteorological forcings and evaporation are not well understood.

The difficulty of actual evaporation estimation results largely from the parameterization scheme for surface fluxes. The TP has a distinct seasonal march of surface energy and water budgets. Sensible heat flux dominates the surface energy budget prior to the monsoon. With frequent rainfall events during the monsoon, latent heat flux overrides sensible heat flux and becomes the dominant surface heat flux. However, current models generally fail to reproduce surface fluxes over the TP because of unreasonable flux parameterization schemes [18]. An improved land surface model with a new flux parameterization scheme was recently applied on the TP surface, and the simulation was comparable to field observation [19]. In this study, the model is used to reproduce the water budget in the source region. Based on this reproduction, new insights are gained concerning water budget response to recent climatic changes.

\section{Data and method}

The data include discharge observation records at Tangnag hydrologic station and long-term, 6-h data from seven China Meteorological Administration (CMA) stations in the source region. Discharge records are available from 1956 to 2008. The CMA data include precipitation, air temperature, wind speed, relative humidity, surface pressure, and sunshine duration. This dataset is complete since 1960 at six stations (Maduo, Xinghai, Dari, Ruoergai, Jiuzhi and Hongyuan), and since 1967 at Maqu. Station locations are shown in Figure 1. The source region is divided into four subbasins (above Maduo, Maduo to Jimai, Jimai to Maqu, and Maqu to Tangnag), according to the asymmetrical station distribution. A Lepage-type statistic [20] was adopted to investigate decadal variation of the aforementioned variables. Furthermore, data from an additional 25 stations surrounding the region (also shown in Figure 1) were included, to capture the spatial distribution of meteorological forcings and their variation.

The model used is an improved simple biosphere scheme (SiB2) [21] rather than a distributed hydrologic model, because the latter requires gridded forcing data that are difficult to create from very limited observations in this complex-terrain region. Improvements to $\mathrm{SiB} 2$ include implementation of an aerodynamic canopy model suitable for short and sparse vegetation [22], a new flux parameterization scheme for bare soils [23], high-accuracy soil water flow [24], physical parameterization of soil-surface evaporation resistance [19], and a scheme for soil freeze/thaw processes [25]. The revised model can substantially improve simulation over the original model, specifically the reproduction of surface energy and water budgets over the TP (see Yang et al. [19] for more details). The surface water budget was simulated at stations in each subbasin, and its contribution to total discharge was estimated according to the weight coefficients of Table 1 . These weights refer to

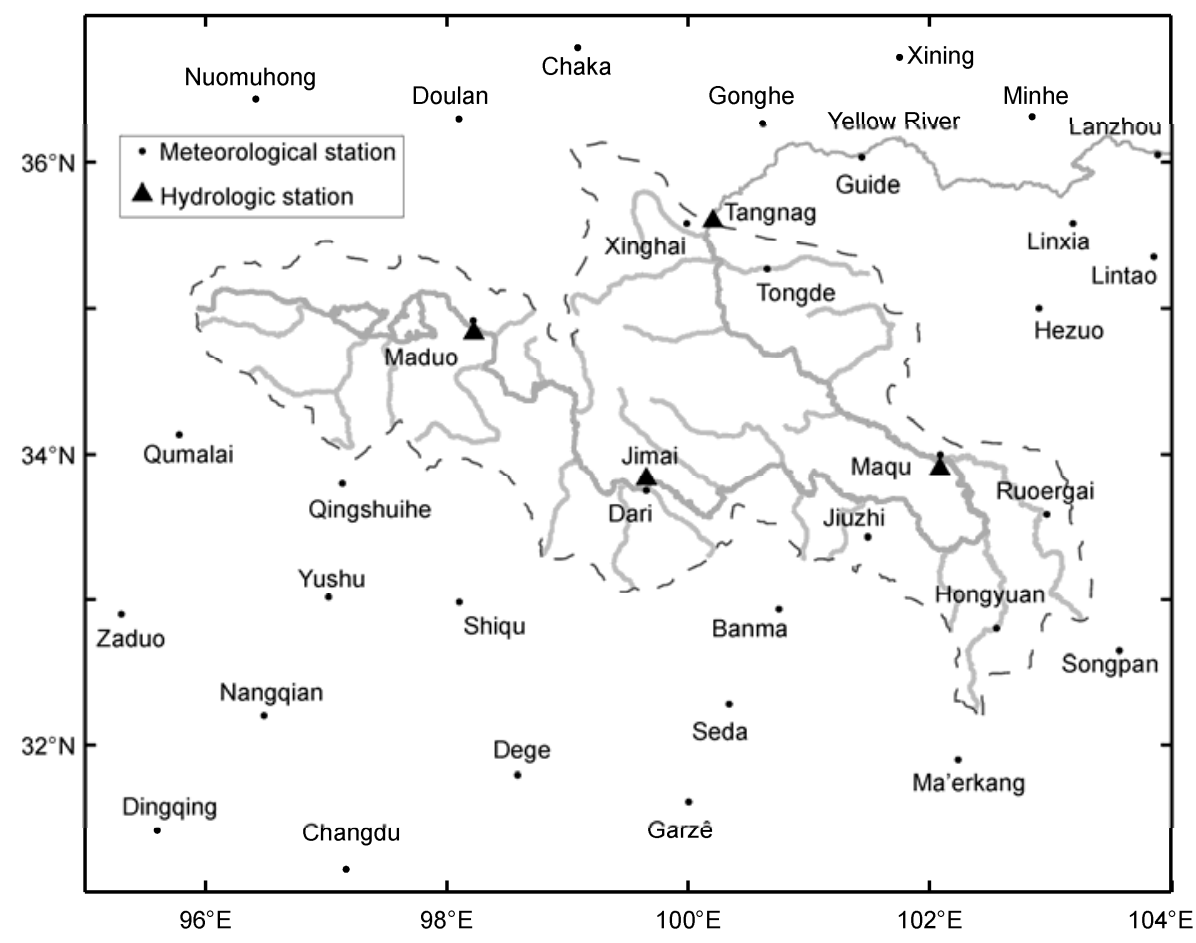

Figure 1 CMA station locations in and surrounding source region of Yellow River basin. 
Table 1 Weight coefficients of total CMA stations in each subbasin of the source region

\begin{tabular}{lccc}
\hline \multicolumn{1}{c}{ Total CMA stations } & Maduo & Dari & Jiuzhi, Hongyuan, Ruoergai, Maqu \\
\hline Sub basin & Above Maduo & From Maduo to Jimai & From Jimai to Maqu \\
Proportion of sub-basin area [1] $^{\text {(1] }}$ & 0.172 & 0.197 & 0.337 \\
Weight coefficient $^{\text {) }}$ & 0.270 & 0.197 & 0.337 \\
\hline
\end{tabular}

a) Since Maduo, Dari and Maqu stations are near the outlets of their respective subbasins, part of each downriver subbasin area (the area is set equal to half the subbasin area from Maduo to Jimai hydrologic stations) is shifted into the upriver sub basin for representativeness of interior CMA stations. Specifically, Maduo station is set as representative of the subbasin above its location and half of sub basin area from Maduo to Jimai; its weight coefficient is set to $0.270(=0.172+0.197 / 2)$. Weight coefficients of Dari station and of the total of Jiuzhi, Hongyuan, Ruoergai and Maqu stations are set equal to the proportions of their corresponding subbasin areas. The weight coefficient of Xinghai station is set to 0.196.

the proportion of each subbasin area within the source region [1]. Glacier runoff, mainly from the A'nyêmaqên Mountains, is of little consequence to total runoff in the region [26], and is thereby not considered.

In the modeling, we set soil parameters and vegetation parameters (classification and coverage) according to $1^{\circ} \times 1^{\circ}$ ISLSCP II (International Satellite Land Surface Climatology Project Initiative II) soil [27] and vegetation data [28]. Leaf area index (LAI) data were sourced from the Moderate Resolution Imaging Spectroradiometer (MODIS) $0.25^{\circ} \times$ $0.25^{\circ}$ gridded 8-d LAI dataset [29]. Meteorological forcings at the aforementioned 32 stations were used as forcing data for surface process modeling. CMA 6-h data were too coarse to represent the large diurnal variations of meteorological forcings at high altitude (mostly over 3000 m ASL) and the influence of strong solar heating. Thus, a downscaling method [30] based on statistical relationships derived from high-resolution experimental data was used to obtain an hourly dataset for the simulation. The simulated period began in 1952, and climatologic data were used to drive the model until observations were available. The water budget was investigated over the period 1960-2006.

\section{Observation diagnoses}

\subsection{Observed changes in runoff and meteorological forcings}

We initially investigate variations of runoff and regional mean meteorological forcings in the source region during 1960-2008. A sudden shift of runoff since 1990 noted by Lan et al. [2] was also identified here by the Lepage test [20]. Runoff prior to 1990 averaged $220.5 \times 10^{8} \mathrm{~m}^{3}$, but afterward the average decreased significantly, reaching only $170.6 \times 10^{8} \mathrm{~m}^{3}$ (Figure 2(a)). The variation of regional mean annual precipitation was similar to runoff, but not always consistent with it (Figure 2(b)). Precipitation was relatively abundant in the early $1980 \mathrm{~s}$, and averaged $524.5 \mathrm{~mm}$ before 1990. From 1990 to 2002, the average decreased significantly, to $491.5 \mathrm{~mm}$. Precipitation increased after 2002 (average $538.3 \mathrm{~mm}$ ), but discharge remained low. The surface warmed significantly, with a mean trend of $0.31^{\circ} \mathrm{C}$ per decade (Figure 2(c)). This warming has accelerated over the last 30 years. This warming trend approaches the average for the TP [4], which greatly exceeds the Northern Hemisphere average [3]. Wind speed after 1969 steadily decreased at a rate of about $0.13 \mathrm{~m} \mathrm{~s}^{-1}$ per decade (Figure 2(d)). Such wind speed reduction is common in China, and it might indicate monsoon weakening [31]. Relative humidity had no obvious trend before 1990, but from 1990 onward, it decreased (Figure 2(e)). Specific humidity clearly increased, at $0.05 \mathrm{~g} \mathrm{~kg}^{-1}$ per decade (Figure 2(f)). Sunshine duration had no clear decadal variation (not shown). In summary, similar to variations in other parts of the TP [4], the source region experienced rapid changes including decadal warming, moistening and wind speed decrease. Precipitation decreased in the 1990 s but ample precipitation returned after 2002. Discharge remained low after 1990.

\subsection{Relationships between runoff and meteorological forcings}

We now address the abnormal low runoff after 1990 and its correlation with regional mean meteorological forcings. Although the variation of precipitation is not always consistent with runoff, their correlation coefficient reaches 0.80 and passes the $t$-test at the level $P<0.05$. Therefore, precipitation is a strong and direct influence on runoff, as argued by Liu and Chang [7] and Zhao et al. [14]. Relative humidity also has a significant positive correlation with runoff. The correlation coefficient between surface air temperature and runoff is -0.28 and fails to pass the test $(P<0.05)$, similar to Niu and Zhang [8]. The decline of relative humidity after 1990 and the rapid warming imply that increasing saturation deficit may enhance evaporation and reduce runoff. Regional mean sunshine duration also has a negative correlation (-0.36) with runoff, but has no obvious decadal trend, which means that their correlation is mainly on an interannual scale. Other meteorological forcings have no significant correlation with runoff.

Previous studies $[13,14]$ have asserted that the decrease of precipitation intensity in the 1990s was an important cause of low runoff in the region, because light rainfall generally produces less direct runoff. We thus investigated the variation of precipitation intensity. Rainfall was stratified into three intensity classes: Small $(<10 \mathrm{~mm}$ per day), middle (10-25 $\mathrm{mm}$ per day) and heavy ( $>25 \mathrm{~mm}$ per day). Figure 3 shows variation of days of these three kinds of 

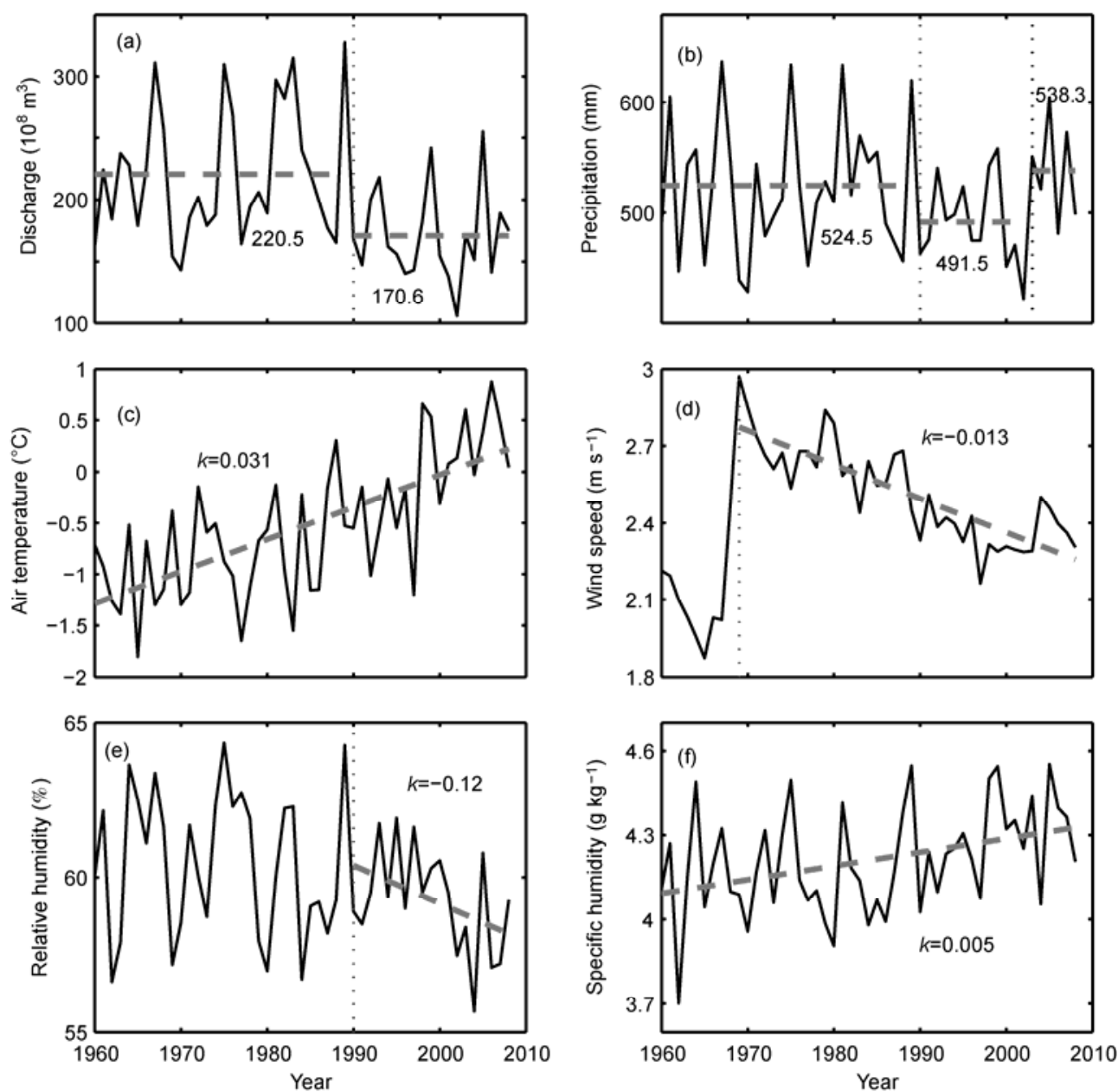

Figure 2 Variations of gauged discharge (a) at Tangnag hydrologic station, and regional average meteorological forcings including precipitation (b), air temperature (c), wind speed (d), relative humidity (e) and specific humidity (f) from 1960 to 2008; $k$ is line slope.
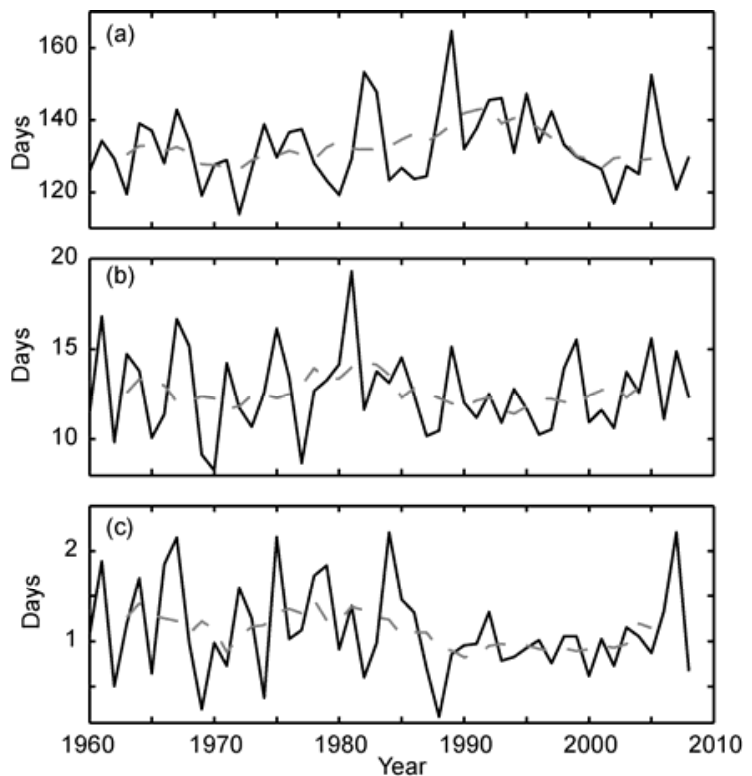

Figure 3 Variations of number of days (annual average) for small rainfall ( $<10 \mathrm{~mm}$ per day) (a), middle rainfall (10-25 $\mathrm{mm}$ per day) (b) and heavy rainfall ( $>25 \mathrm{~mm}$ per day) (c). Bold dashed lines represent 7-point smoothing. rainfall, averaged regionally and annually. The number of days with small rainfall was above normal during the early 1990s, and then deceased after 2000 (Figure 3(a)). In contrast, days of middle and heavy rainfall were below normal in the 1990s, but increased in recent years (Figure 3(b),(c)). This implies that the variation of precipitation intensity in recent years may increase direct surface runoff. This is not consistent with the observed low runoff after 2002, when precipitation recovered to above normal levels.

The meteorological forcings in Figure 2, except precipitation, had similar changes or trends at the CMA stations. Sunshine duration had a clear increase only at Maduo, and a decrease only at Dari. As shown in Figure 4(a), the distribution of mean annual precipitation in the source region is very uneven. The annual precipitation is over $500 \mathrm{~mm}$ in the southeastern part of the region, because of the Asian summer monsoon, while it is $500 \mathrm{~mm}$ or less in the north and west. The southeast is the principal area of runoff generation in the source region [32]. The subbasin from Jimai to Maqu hydrologic stations, $33.7 \%$ of the entire area, contributes $55.7 \%$ of the discharge [1]. Figure 4(b) shows the spatial distribution of precipitation anomaly from 1990 to 2002 . 

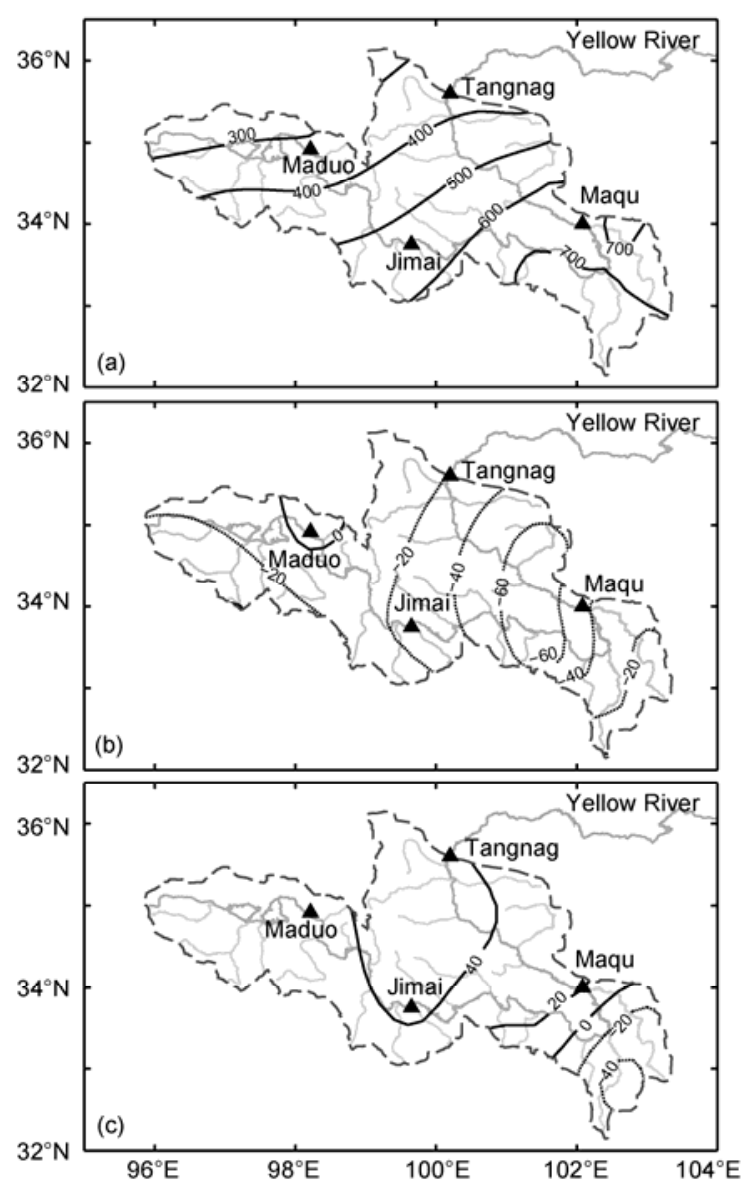

Figure 4 Spatial distributions in the Yellow River source region for precipitation: (a) annual amount, and (b) anomaly from 1990 to 2002 and (c) after 2002. Unit: $\mathrm{mm}$.

Only near Maduo was there a small increase in precipitation, while it decreased more than $40 \mathrm{~mm}$ in the center and southeast. This caused below normal basin-averaged annual precipitation over the period. After 2002, the negative anomaly area shrank to the area where annual precipitation was more than about $700 \mathrm{~mm}$. However, a larger positive precipitation anomaly area appeared in the north and west (Figure 4(c)), leading to above normal basin-averaged annual precipitation. Such spatial variations may affect the generation of runoff.

Therefore, the persistent low runoff after 2002 cannot be explained by the variations of precipitation amount and intensity. However, the spatial variation of precipitation may be an important influence. The changes of other meteorological forcings, especially the decline of relative humidity and warming, may enhance evaporation and in turn reduce runoff. The disintegration of permafrost might also affect soil water seasonal storage and diminish surface runoff $[13,33]$. These processes are believed to account for the persistent low runoff after 1990. To assist our analysis, land surface modeling was used to reproduce surface hydrologic processes.

\section{Surface water budget}

\subsection{Evaluation of simulated runoff}

Surface water budget was simulated at individual CMA stations using the improved SiB2. Figure 5(a) shows a comparison of inter-annual variability of simulated runoff depth versus observed. Observed runoff depth was calculated by gauged discharge at Tangnag station divided by total area of the region. Simulated runoff depth is the average of simulated runoff depths at all individual stations within the source region, weighted by the coefficients of Table 1. The result indicates that inter-annual variability of runoff was well simulated. In particular, the simulated anomaly after the late 1980s was the same as observed. Moreover, the simulated annual runoff depth approximated the observation (observed runoff depth was $165.5 \mathrm{~mm}$, and the simulated weighted average without model calibration was $178.8 \mathrm{~mm}$ ). These indicate that the regional surface water budget was reasonably reproduced by simple 1-D land surface modeling. Therefore, the simulated water budget (runoff and evaporation) may be used to investigate its response to recent climatic changes.

\subsection{Climatic change in surface water budget}

Figure 5(b) shows the variation of annual evaporation anomaly in the source region. The simulated evaporation increases at $7.5 \mathrm{~mm}$ per decade, passing the $t$-test $(P<0.05)$. Its standard deviation is less than for precipitation (Figure 2(b)) and runoff depth (Figure 5(a)), which suggests that precipitation is a direct influence on regional runoff. Simulated evaporation in the early 1980s was greater than before.
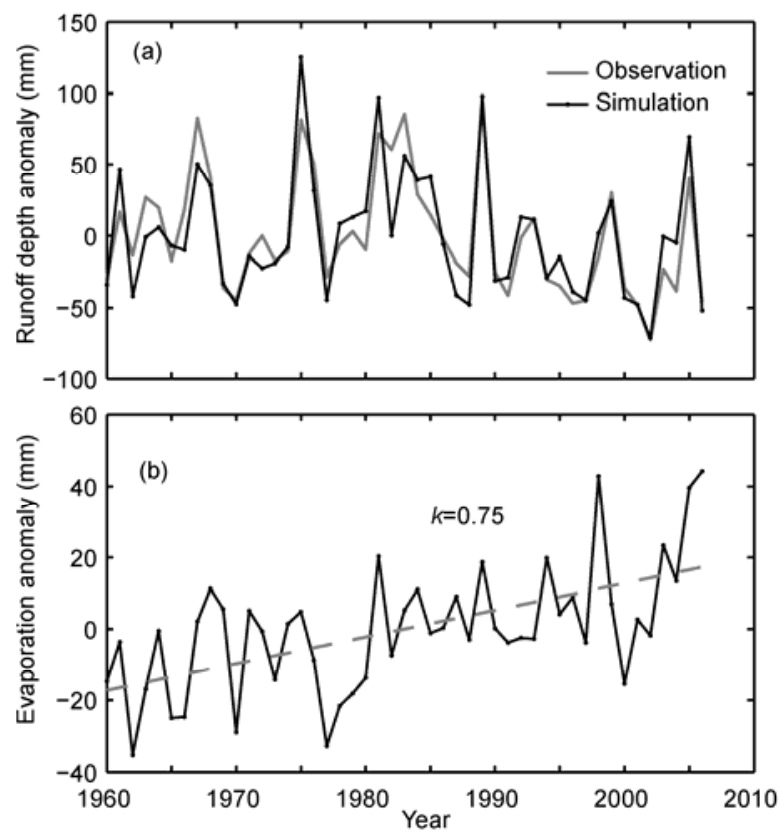

Figure 5 (a) Comparison of simulated runoff depth against observed; (b) anomaly of simulated annual evaporation. $k$ is line slope. 
After 2002, the positive anomaly strengthened further, largely compensating the increase of regional precipitation; this explains the persistently low runoff.

Soil water storage is another component in the hydrologic cycle. However, the trend of simulated annual surface soil moisture is very weak in the source region, and can be negligible in comparison with the variations of precipitation, runoff and evaporation. Therefore, we believe that regional runoff is mainly controlled by precipitation and evaporation on an annual scale.

Evaporation in the region also decreases from southeast to northwest, similar to the spatial distribution of precipitation in Figure 4(a). Figure 6(a) shows the spatial distribution of evaporation anomaly from 1990 to 2002. The anomaly was slightly positive in the southeast and in part of the northwest, and it was negative in the northeast, leading to the near normal basin-average annual evaporation. After 2002, all evaporation anomalies became positive (Figure 6(b)), with greater strengthening in the southeast and west. Based on spatial variation of evaporation and precipitation anomalies shown by Figures 4 and 6, the surface water balance has changed. The runoff yield anomaly in the northwest region changed only slightly after 1990, because the increase/decrease of evaporation approached the increase/ decrease of precipitation. Runoff yield in the northeast declined somewhat between 1990 and 2002, because precipitation decrease exceeded evaporation decrease. This yield escalated after 2002 , because precipitation increase overrode evaporation increase. The yield in the southeast, the key area for runoff generation, decreased considerably after 1990 because of the decline in precipitation together with evaporation increase. This was especially so after 2002;
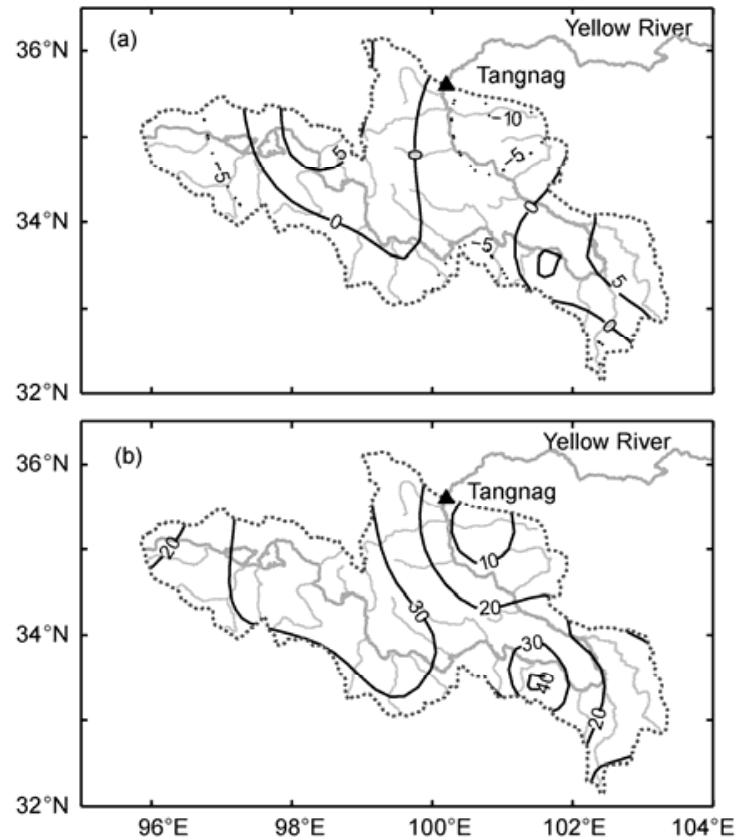

Figure 6 Spatial distribution of evaporation anomaly in the source region: (a) from 1990 to 2002, and (b) after 2002. Unit: mm. although precipitation slightly increased, it was offset by more increase of evaporation. This reduced runoff generation. Therefore, the significant discharge decrease at Tangnag hydrologic station after 1990 is mainly attributable to declining runoff yield in the southeast part of the region.

\subsection{Response of evaporation to climatic changes}

Simulated evaporation (Figure 5(b)) exhibits significant positive correlation with regional mean precipitation, air temperature and specific humidity, and negative correlation with wind speed after 1969. Variations of some meteorological forcings such as precipitation and solar radiation differ with the station, and surface warming, moistening and wind speed decrease occurred simultaneously in the source region. Consequently, we calculated correlation coefficients $(R)$ only between evaporation $\left(E_{\mathrm{v}}\right)$ and precipitation $(\operatorname{Pr})$, air temperature $\left(T_{\mathrm{a}}\right)$, and solar radiation $\left(R_{\mathrm{sw}}\right)$ at individual stations. The correlation coefficients at annual scale are shown in Table 2. The dry area (mean annual precipitation less than $500 \mathrm{~mm}$ ) and wet area (mean annual precipitation more than $500 \mathrm{~mm}$ ) have distinct statistical characteristics overall. The $R\left(P r, E_{\mathrm{v}}\right)$ values are positive and significant in the dry area, but they decline toward the wet area. The $R\left(T_{\mathrm{a}}, E_{\mathrm{v}}\right)$ and $R\left(R_{\mathrm{sw}}, E_{\mathrm{v}}\right)$ values are typically small and insignificant in the dry area, but positive and generally significant in the wet area. These results imply that evaporation at annual scale is mainly water-limited in the dry area, as energy is sufficient for forcing evaporation but precipitation is limited. This is different from Lan et al. [32], which assumed that the increase of evaporation in this area was mainly caused by the rapid warming. In the wet area, however, evaporation is restricted by both water and energy. From the dry stations to wet stations, water gradually becomes sufficient, and energy becomes more important for forcing evaporation.

Therefore, the increase/decrease of precipitation in the dry area after 1990 caused the increase/decrease of evaporation, and the rapid warming somewhat contributed to

Table 2 Correlation coefficients between annual mean values of forcings and simulated evaporation at individual stations ${ }^{\text {a) }}$

\begin{tabular}{lcccc}
\hline \multicolumn{1}{c}{ Station } & $P r(\mathrm{~mm})$ & $R\left(\operatorname{Pr}, E_{\mathrm{v}}\right)$ & $R\left(T_{\mathrm{a}}, E_{\mathrm{v}}\right)$ & $R\left(R_{\mathrm{sw}}, E_{\mathrm{v}}\right)$ \\
\hline Maduo & 311.7 & $0.641^{*}$ & $0.474^{*}$ & -0.023 \\
Xinghai & 354.9 & $0.795^{*}$ & 0.096 & -0.226 \\
Tongde $^{\mathrm{b})}$ & 425.9 & $0.571^{*}$ & 0.278 & -0.070 \\
Dari & 545.9 & $0.382^{*}$ & $0.659^{*}$ & $0.461^{*}$ \\
Maqu & 601.6 & 0.210 & $0.605^{*}$ & $0.569^{*}$ \\
Ruoergai & 649.9 & $0.353^{*}$ & $0.645^{*}$ & $0.446^{*}$ \\
Hongyuan & 750.1 & 0.245 & $0.474^{*}$ & 0.045 \\
Jiuzhi & 752.8 & 0.289 & $0.669^{*}$ & $0.484^{*}$ \\
\hline
\end{tabular}

a) $\operatorname{Pr}, E_{\mathrm{v}}, T_{\mathrm{a}}$ and $R_{\mathrm{sw}}$ denote precipitation, evaporation, surface air temperature and downward solar radiation, respectively. b) Water budget at Tongde station is simulated only during 1954-1998, since meteorological data after 1998 is unavailable. * means that coefficient passes the $t$-test $(P<0.05)$. 
increased evaporation. This led to the weak change of runoff generation in the north and west. In the wet area, however, both the decrease of precipitation and increase of evaporation responding to rapid warming after 1990 were principal causes of the decreased runoff generation. Even though regional precipitation rose to above normal levels after 2002, this increase was mainly in the dry area. Therefore, this increased precipitation was largely evaporated, contributing little to the variation of runoff generation. Precipitation in parts of the wet area also increased, but was accompanied by an evaporation increase from warming, so there was no enhancement of runoff generation. All these factors resulted in the persistently low discharge after 1990, despite the above-normal precipitation after 2002.

\section{Concluding remarks}

The source region of the Yellow River has experienced rapid warming, moistening and weakening wind speeds over recent decades. Precipitation decreased in the 1990s, but ample precipitation returned after 2002; nevertheless, discharge remained low after 1990. This study investigated water budget response in the region to recent climatic changes. Precipitation is obviously a direct influence on runoff, at either regional scale or individual stations. However, the low runoff after 1990 cannot be fully explained by variation of precipitation amount and intensity. We found that the spatial pattern of precipitation change is another important factor in the response of runoff to precipitation change. In the dry area of the region (north and west), runoff is not very sensitive to precipitation change. This is because evaporation there is principally limited by water availability, and thus most of the precipitation change is evaporated. Therefore, runoff generation in the dry area contributes relatively little to total runoff; its variation was relatively slight, both in the 1990 s when precipitation was below normal and during recent years, when it was above normal. On the other hand, runoff change in the wet area of the source region (southeast) is sensitive to precipitation change. Energy availability in this area is more important for determining evaporation. Consequently, in the 1990s increased evaporation occurred because of rapid warming, despite a precipitation decrease. More evaporation increase overrode slight increase of precipitation after 2002, contributing to a remarkable decline in runoff generation. These two phenomena are primarily responsible for the current, persistent low discharge.

This work was supported by the National Basic Research Program of China (2009CB421405). We would like to thank the two anonymous reviewers for their constructive criticisms and helpful comments.

1 Zhao W M, Wang Q Z, Liu X W, et al. Study on the Runoff Yield in the Typical Hydrologic Regions of the Yellow River (in Chinese).
Zhengzhou: Yellow River Conservancy Press, 2006. 1-233

2 Lan Y C, Kang E S, Ma Q J, et al. The trend predication and characteristics of variation of the runoff into the Longyangxia Reservior (in Chinese). J Glaciol Geocryol, 1999, 21: 281-285

3 Liu X D, Chen B D. Climatic warming in the Tibetan Plateau during recent decades. Int J Climatol, 2000, 20: 1729-1742

4 Kang S C, Xu Y W, You Q L, et al. Review of climate and cryospheric change in the Tibetan Plateau. Environ Res Lett, 2010, 5: 015101

5 Gou X H, Deng Y, Chen F H, et al. Tree ring based streamflow reconstruction for the upper Yellow River over the past 1234 years. Chin Sci Bull, 2010, 55: 4179-4186

6 Li D F, Tian Y, Liu C M, et al. Impact of land-cover and climate changes on runoff of the source regions of the Yellow River. J Geogr Sci, 2004, 14: 330-338

7 Liu X Y, Chang X H. A summary of study on runoff variations in source region of the Yellow River (in Chinese). Yellow River, 2005, 27: 6-14

8 Niu Y G, Zhang X C. Preliminary analysis on variations of hydrologic and water resources regime and its genesis of the Yellow River source region (in Chinese). Yellow River, 2005, 27: 31-36

9 Chen L Q, Liu C M. Influence of climate and land-cover change on runoff of the source regions of Yellow River (in Chinese). Chin Environ Sci, 2007, 27: 559-565

10 Chen L Q, Liu C M, Li Y P, et al. Impacts of climatic factors on runoff coefficients in source regions of the Huanghe River. Chin Geogr Sci, 2007, 17: 47-55

11 Zhang X S, Srinivasan R, Debele B, et al. Runoff simulation of the headwater of the Yellow River using the SWAT model with three snowmelt algorithms. J Am Water Resour As, 2008, 44: 48-61

12 Lan Y C, Zhao G H, Zhang Y N, et al. Response of runoff in the source region of the Yellow River to climate warming. Quat Int, 2010, 226: 60-65

13 Zhou D G, Huang R H. Exploration of reason of runoff decrease in the source regions of the Yellow River (in Chinese). Clim Environ Res, 2006, 11: 302-309

14 Zhao R R, Chen H C, Zhu S L, et al. Analysis on variations of runoff and reasons of headwater region of the Yellow River (in Chinese). Yellow River, 2007, 29: 15-16

15 Qiu X F, Liu C M, Zeng Y. Changes of pan evaporation in the recent 40 years over the Yellow River basin (in Chinese). J Nat Resour, 2003, 18: 437-442

16 Li L, Zhang G S, Wang Q C, et al. Dry climate impact on evapotranspiration in the upper valley of the Yellow River (in Chinese). Meteorol Mon, 2000, 26: 6-10

17 Shi X H, Qin N S, Wang Q C, et al. Analysis on runoff variation characteristics and influencing factors in the upper Yellow River (in Chinese). J Desert Res, 2007, 27: 690-697

18 Yang K, Rasmy M, Rauniyar S, et al. Initial CEOP-based review of the prediction skill of operational general circulation models and land surface models. J Meteorol Soc Jpn, 2007, 85A: 99-116

19 Yang K, Chen Y Y, Qin J. Some practical notes on the land surface modeling in the Tibetan Plateau. Hydrol Earth Syst Sci, 2009, 13: 687-701

20 Lepage Y. A combination of Wilcoxon's and Ansari-Bradley's statistics. Biometrika, 1971, 58: 213-217

21 Sellers P J, Randall D A, Collatz G J, et al. A revised land surface parameterization ( $\mathrm{SiB} 2)$ for atmospheric GCMs. Part I: Model formulation. J Clim, 1996, 9: 676-705

22 Watanabe T, Kondo J. The influence of canopy structure and density upon the mixing length within and above vegetation. J Meteorol Soc Jpn, 1990, 68: 227-235

23 Yang $\mathrm{K}$, Koike $\mathrm{T}$, Ishikawa $\mathrm{H}$, et al. Turbulent flux transfer over bare-soil surfaces: Characteristics and parameterization. J Appl Meteorol Clim, 2008, 40: 276-290

24 Ross P J. Modeling soil water and solute transport-fast, simplified numerical solutions. Agron J, 2003, 95: 1352-1361

25 Li Q, Sun S F, Dai Q D. The numerical scheme development of a simplified frozen soil model. Adv Atmos Sci, 2009, 26: 940-950 
26 Yang J P, Ding Y J, Liu S Y, et al. Glacier change and its effect on surface runoff in the source regions of the Yangtze and Yellow rivers (in Chinese). J Nat Resour, 2003, 18: 595-602

27 Global Soil Data Task Group. Global Gridded Surfaces of Selected Soil Characteristics (IGBPDIS), International Geosphere-Biosphere Programme-Data and Information Services. Oak Ridge National Laboratory Distributed Active Archive Center, Oak Ridge, Tennessee, USA, 2000

28 Loveland T R, Reed B C, Brown J F, et al. Development of a global land cover characteristics database and IGBP DISCover from 1-km AVHRR data. Int J Remote Sens, 2001, 21: 1303-1330

29 Knyazikhin Y, Glassy J, Privette J L, et al. MODIS Leaf Area Index (LAI) and Fraction of Photosynthetically Active Radiation Absorbed by Vegetation (FPAR) Product (MOD15) Algorithm Theoretical Basis Document Version 4.0. 1999

30 Yang K, Qin J, Guo X F, et al. Method development for estimating sensible heat flux over the Tibetan Plateau from CMA data. J Appl Meteorol Clim, 2009, 48: 2474-2486

31 Jiang Y, Luo Y, Zhao Z C, et al. Changes in wind speed over China during 1956-2004. Theor Appl Climatol, 2010, 99: 421-430

32 Lan Y C, Zhao G H, Zhang Y N, et al. Response of runoff in the headwater region of the Yellow River to climate change and its sensibility analysis. J Geogr Sci, 2010, 20: 848-860

33 Xie C W, Ding Y J, Liu S Y. Changes of weather and hydrological environment for the last 50 years in the source regions of Yangtze and Yellow Rivers (in Chinese). Ecol Environ, 2004, 13: 520-523

Open Access This article is distributed under the terms of the Creative Commons Attribution License which permits any use, distribution, and reproduction in any medium, provided the original author(s) and source are credited. 